\title{
Capacidade Transformativa e Crescimento Econômico: Uma Análise para os Municipios Brasileiros
}

\author{
Adilson Giovanini $^{1}$ (D) | Beatriz Vasconcelos Sabino Reis ${ }^{2}$ \\ ${ }^{1}$ Universidade do Estado de Santa Catarina. E-mail: adilsoneconomia@gmail.com \\ ${ }^{2}$ Universidade do Estado de Santa Catarina. E-mail: bia_vsr@hotmail.com
}

\begin{abstract}
RESUMO
Apesar da literatura de capacidade estatal defender a importância da Capacidade transformativa para o desenvolvimento econômico, não foram encontrados estudos na literatura de desenvolvimento regional que a diferenciassem das políticas de incentivo produtivo e das Instituições. Esse artigo desenvolve indicadores específicos de instituições e capacidade transformativa e utiliza a análise fatorial para elaborar dois indicadores de incentivo produtivo para 4.359 municípios brasileiros. Ferramentas de correlação e regressões espaciais diferenciam essas capacidades e identificam se elas resultam em maiores taxas de crescimento do PIB per capita. Os resultados mostram que parte significativa dos municípios exibem baixo desenvolvimento dessas capacidades, sendo elas observadas com maior frequência nos municípios das Regiões Sul, Sudeste e Centro-Oeste do país. A sua presença resulta em taxas mais elevadas de crescimento econômico, inclusive para os municípios vizinhos, o que evidencia a importância das arenas de diálogo definidas pelo Estado em sinergia com a iniciativa privada.
\end{abstract}

\section{PALAVRAS-CHAVE}

Capacidade transformativa, Instituições, Políticas produtivas, Econometria espacial, Municípios brasileiros

Transformative Capacity and Economic Growth: An Analysis for Brazilian Municipalities

\begin{abstract}
Despite the literature on state capacity defending the importance of transformative capacity for economic development, no studies were found in the regional development literature that differentiated it from productive incentive policies and institutions. This article develops specific indicators of institutions and transformative capacity and uses factor analysis to develop two indicators of productive incentive for 4,359 Brazilian municipalities. Correlation tools and spatial regressions differentiates theses capacities and identify whether they result in higher GDP growth rates per capita. The results show that a significant part of the municipalities exhibits low development of these capacities, being observed more frequently in the municipalities of the South, Southeast and Midwest regions of the country. Its presence results in higher rates of economic growth, including for neighboring municipalities, which shows the importance of thearenas of dialogue defined by the State in synergy with the private initiative.
\end{abstract}

\section{KEYWORDS}

Transformative capacity, Institutions, Productive policies, Spatial econometrics, Brazilian municipalities

\section{CLASSIFICAÇÃO JEL}

O18, R38, R58 


\section{Introdução}

Solow (1956), Swan (1956), Romer (1986), Lucas (1988) e Barro (1990) desenvolveram modelos de crescimento econômico e convergência de renda que enfatizam a importância da acumulação de capital físico e humano para o crescimento econômico regional. Esses modelos são complementados pela literatura nacional, que destaca a contribuição dos gastos públicos (Barro, 1991; Easterly e Rebelo, 1993; Oliveira et al., 2018); das instituições (Leivas et al., 2015; Santana e Barreto, 2016) e da inovação (Ferreira Neto, 2014; Almeida et al., 2017; Casagrande et al., 2017; Silva et al., 2018; Faria et al., 2018) para o crescimento econômico.

Paralelo à essa discussão, a literatura internacional de capacidade estatal exibe importante coleção de evidências sobre os instrumentos à disposição do Estado e sobre o seu escopo de atuação. Ela argumenta que os governos possuem um modus operandi que pode ser discriminado em diferentes dimensões de Capacidade estatal (Gerschenkron, 1968; Johnson, 1982; Weber, 1994; Evans et al., 1985; Amsden, 2001; Wade, 2018; Weiss, 2018; Evans, 2012; Tilly, 2007; Painter e Pierre, 2005). Para além de uma administração autônoma e insulada (Weber, 1994) o Estado deve promover o diálogo com a sociedade e desenvolver instituições, políticas e instrumentos voltados para a transformação na estrutura produtiva (Evans et al., 1985; Evans, 1993). A literatura de Capacidades estatais se soma às literaturas pioneiras que identificaram a importância do Estado para o crescimento econômico. Com destaque para o gasto público (Keynes, 2018), a realização de políticas industriais e tecnológicas (Rodrik, 1998; Hausmann e Rodrik, 2003; Suzigan e Furtado, 2006; Almeida, 2009; Cano e Silva, 2010; Mazzucato, 2014; Suzigan, 2017) e as instituições (North et al., 1990; Williamson e Masten, 1999; Hodgson, 2006, 2007).

O conceito de Capacidade estatal foi proposto inicialmente por Evans et al. (1985), que a definem como a habilidade das burocracias estatais em formular e perseguir políticas públicas que não se restringem às demandas dos grupos sociais organizados. Esse conceito é revisitado por Evans (1993) e Evans (2012), para os quais ela não se restringe às características assumidas pelo aparelho estatal e a sua liberdade de decisões. Ela também envolve o modo como o Estado se relacionada com a estrutura social circundante e sua capacidade de gerar incentivos capazes de induzir a burocracia estatal a perseguir metas em parceria com a sociedade. A presença de capacidades que habilitam o Estado a promover o crescimento econômico se mostra de especial relevância (Evans, 1993). Essas capacidades assumem função orientadora, visto que complementam, coordenam e direcionam os esforços privados (Evans, 2004), sendo o termo "Capacidade transformativa" utilizado por Evans (2012) para identificar o papel basilar do Estado em ofertar os meios necessários para a realização de mudanças na estrutura produtiva.

Apesar de a literatura de capacidade estatal (Evans, 2012; Weiss, 2018; Cingolani, 2013) defender que a Capacidade transformativa contribui para o crescimento 
econômico, se observa uma carência de estudos sobre esse tema na literatura de desenvolvimento regional. No decorrer da revisão de literatura foram encontrados apenas estudos que identificam se o desenvolvimento institucional resulta em maiores taxas de crescimento da renda per capita (Leivas et al., 2015; Santana e Barreto, 2016). Não foram identificados estudos que diferenciassem o conceito de Capacidade transformativa do conceito de Instituições e de políticas produtivas.

Destarte, se justifica a corrente pesquisa, que diferencia esses conceitos e verifica se a sua presença resulta em maiores taxas de crescimento da renda per capita. Precisamente, esse artigo possui três objetivos: 1. desenvolver indicadores de capacidade transformativa, capacidade institucional e políticas produtivas para os municípios brasileiros; 2. identificar o padrão de distribuição espacial desses indicadores; e, 3. verificar se a sua presença resulta em maiores taxas de crescimento econômico para os municípios brasileiros e seus vizinhos.

Para alcançar esses objetivos se recorre à análise descritiva de dados e à análise fatorial, utilizada para construir dois índices de políticas produtivas. O coeficiente $I$ de Moran global e o coeficiente $I_{i}$ de Moran local (LISA) identificam a padrão de distribuição espacial dos dados e regressões espaciais testam se a presença de Capacidade transformativa resulta em taxas mais elevadas de crescimento na renda per capita. As regressões são estimadas para uma amostra composta por 4.359 municípios brasileiros a partir de dados de 2015, exceto para os indicadores de Capacidade transformativa e Instituições, construídos com dados de diversos anos.

Os resultados encontrados corroboram a hipótese levantada, os indicadores construídos conseguem diferenciar as instituições das políticas de incentivo à novos empreendimentos e da capacidade transformativa. Eles mostram que essas políticas resultam em maiores taxas de crescimento econômico, inclusive para os municípios vizinhos, exibindo efeito espacial. Esses resultados evidenciam a importância das capacidades transformativas, a presença nos governos locais dos aparatos e instrumentos necessários lhes dotam dos meios para formarem uma agenda, construírem arenas de diálogo com a sociedade, alinharem e sensibilizarem as forças locais e proporem iniciativas voltadas para a estrutura produtiva, o que se traduz em maior desenvolvimento econômico regional, maior estabilidade econômica e em um ambiente mais favorável ao setor privado.

Além dessa introdução, o artigo segue estruturado em mais quatro seções. A seção 2 revisa a literatura de Capacidade transformativa. Na sequência, a seção 3 discorre sobre os métodos e procedimentos econométricos adotados. Posteriormente, a seção 4 exibe os resultados encontrados. Finalmente, a seção 5 realiza algumas considerações finais. 


\section{Capacidades estatais e transformativas: uma discussão à luz das evidências teóricas}

A literatura que aborda as características exibidas pelo aparato administrativo estatal discorre sobre a importância das capacidades estatais (state capacities) e sobre o papel do Estado como responsável por elaborar e implementar políticas públicas, além de derivar diferentes definições para o conceito de capacidades estatais. Tilly (2007) define Capacidades estatais como a habilidade dos agentes estatais em intervir e promover a modificação na distribuição dos recursos não estatais. Marenco (2017), por sua vez, argumenta que para executar as suas funções as organizações estatais necessitam de um aparato burocrático, capaz de empregar meios como a coerção e a regulamentação para alcançar os seus objetivos, ainda que isso implique em modificar atributos como o status quo, a renda e os direitos de propriedade previamente definidos.

Evans (2012), por sua vez, ressalta que a presença de uma burocracia weberiana autônoma e insulada resulta em ação coerente e coesa, o que possibilita a eficiente implementação de políticas voltadas para a transformação econômica. Ele argumenta que o conceito de capacidade estatal não se limita a uma burocracia racional, qualificada e autônoma. Para além da autonomia, o corpo burocrático do Estado deve possuir capacidade de se relacionar, dialogar e criar conexões com as instituições privadas em defesa do avanço econômico (Evans, 2004). O desenvolvimento de condições que impedem a captura do Estado por interesses privados reside na presença de uma burocracia estatal competente e coesa (Gomide et al., 2014). Daí deriva o conceito de Autonomia Inserida (embedded autonomy), proposto por (Evans, 1993, p. 22) e definido como "uma combinação aparentemente contraditória entre isolamento burocrático weberiano e inserção intensa na estrutura social circundante".

O conceito de Poder infraestrutural, proposto por Mann (1984), dialoga diretamente com o conceito de Autonomia inserida e defende uma relação de cooperação entre os cidadãos e seus governos. Para Mann (1984), a implementação de políticas nos Estados democráticos contemporâneos se encontra estreitamente vinculada à capacidade destes em interagir com os cidadãos e disponibilizar os serviços sociais básicos.

O Estado se encontra inserido em uma complexa teia de relações com atores sociais que recorrem a ele para auferir benefícios. A autonomia possibilitada por uma burocracia weberiana o habilita a formular e perseguir objetivos próprios, voltados para a transformação na estrutura produtiva (Evans, 2004). O termo "Capacidade transformativa” é mobilizado por Evans (2012) para evidenciar a importância da atuação proativa do Estado, voltada para o desenvolvimento da estrutura produtiva. Evans (2002) recorre à Amartya Sen para expandir o conceito de autonomia inserida e defender que o Estado também deve se relacionar com os demais grupos da sociedade, não se restringindo a construir arenas de diálogo com os grupos empresariais. A capacidade do Estado em formular e implementar políticas públicas depende da sua 
capacidade de mobilizar os diferentes grupos sociais para promover o desenvolvimento social inclusivo.

Para Cingolani (2013), a capacidade transformativa se refere à capacidade do Estado em intervir no sistema produtivo, mobilizar iniciativas e moldar a economia. Já (Weiss, 2018, p. 4) a define como a "capacidade do Estado de se adaptar aos choques e pressões externas, gerando meios sempre novos de governar o processo de mudança industrial". O Estado, portanto, é visto como responsável por coordenar a mudança na estrutura produtiva. Ele direciona os recursos e incentiva à cooperação entre os atores organizados, se fazendo imperativa a adequação dos instrumentos devido à necessidade de aprendizado institucional e organizacional, os quais ocorrem de modo incremental e interativo, em resposta às mudanças graduais observadas no contexto econômico, social e político.

A literatura especializada propõe a existência de diferentes dimensões de capacidades estatais (Aguiar e Lima, 2019). A realização de uma análise minuciosa de cada uma foge do escopo dessa pesquisa, que se restringe a identificar as dimensões explicitamente voltadas para a promoção do crescimento econômico. Cingolani (2013), por exemplo, além da Capacidade transformativa, identifica mais seis dimensões de capacidades estatal, a saber: a Dimensão Coercitiva, por meio da qual o Estado garante a ordem pública e protege o território; Dimensão Fiscal, que habilita o Estado a extrair recursos da sociedade para financiar e fornecer bens e serviços públicos; Dimensão Administrativa, que permite ao Estado construir um corpo administrativo capaz de implementar políticas públicas; Dimensão relacional, que habilita as burocracias do Estado a se conectar com os diferentes grupos da sociedade; Dimensão Legal ou regulatória, que atribui ao Estado a tarefa de definir as "regras do jogo" e o modo como são realizadas as interações entre os atores da sociedade; e Dimensão Política, por meio da qual o Estado elabora uma agenda e define as prioridades perseguidas pela sociedade.

Destarte, a literatura especializada em Capacidades estatais defende que a habilidade do Estado em desenvolver aparatos próprios para a promoção do crescimento econômico e a transformação na estrutura produtiva decorre de uma dimensão específica de capacidade estatal: a Capacidade transformativa. A seguir, o conceito de transformação institucional, proposto pela Nova Economia Institucional (NEI), é diferenciado do conceito de capacidade transformativa.

As Instituições remetem à existência de regras formais e informais responsáveis por nivelar o campo de jogo e reduzir as incertezas ao proporcionar segurança, confiança, tranquilidade e direitos de propriedade bem definidos. Elas são definidas como "sistemas duráveis de regras" que "estruturam as relações sociais" (Hodgson, 2006, p. 7), ancoram as expectativas dos agentes, possibilitam a ação ordenada e conferem consistência às atividades humanas em um ambiente de racionalidade limitada e incerteza, no qual a presença de regras e contratos bem definidos se faz necessária, sendo responsáveis por reduzir os custos de transação e possibilitar a realização de 
trocas de forma estável. As instituições são interpretadas como as regras a serem seguidas, ao passo que as organizações, inclusive o Estado, equivalem aos jogadores. As Mudanças institucionais se encontram por detrás das trajetórias seguidas pelos países, mas não ocorrem facilmente, pois a configuração inicial das instituições tende a definir as organizações vencedoras e gerar aprisionamento em torno da configuração inicial (North et al., 1990).

Assim, a Nova Economia institucional (NEI) analisa o desenvolvimento econômico como mudança nas instituições construídas historicamente, sendo a linha de ação do Estado limitada pelas restrições impostas pelo arcabouço institucional vigente. $\mathrm{O}$ Estado é definido como responsável por garantir os interesses individuais, zelar pelos direitos de propriedade e impor o respeito aos contratos. Essa literatura não considera a interação do Estado com os demais agentes como relevante para o crescimento econômico (North et al., 1990; Williamson e Masten, 1999; Hodgson, 2006, 2007; Acemoglu e Robinson, 2012).

Para a literatura de capacidades estatais, por outro lado, o crescimento econômico se encontra intimamente vinculado ao próprio modo como se dá a interação do Estado com a sociedade, sendo derivado da sua capacidade em dialogar com os demais agentes e desenhar políticas públicas em comum consenso. Essa literatura também não realiza uma distinção clara entre o conceito de capacidades estatais e de Instituições, as quais são tomadas como parte das diferentes capacidades possuídas pelo Estado. O conceito de capacidade estatal frequentemente é reduzido ao conceito de Instituições e as variáveis utilizadas para definir capacidade estatal não atendem à definição seminal de Evans (1993, 2004, 2012), de capacidade estatal como a capacidade do Estado de se relacionar e solidarizar interesses privados, sendo utilizadas apenas variáveis que identificam a presença de direitos de propriedade bem definidos e de liberdade econômica (Fortin, 2012).

De modo que a diferenciação entre as definições de Capacidade estatal e Instituições se faz importante para eliminar simplificações encontradas na literatura (Ferreira Neto, 2014; Leivas et al., 2015; Santana e Barreto, 2016; Barreto et al., 2018). O corrente artigo ao construir indicadores que delimitam esses termos de forma mais rigorosa e diferenciar a contribuição do Estado sob a ótica das Instituições e das capacidades transformativas avança nessa discussão.

Os estudos encontrados na literatura especializada definem as políticas de desenvolvimento regional como a habilidade do Estado em centralizar, direcionar e coordenar a transformação na estrutura produtiva (Suzigan e Furtado, 2006; Almeida, 2009; Cano e Silva, 2010; Mazzucato, 2014; Suzigan, 2017). Apesar dos avanços realizados por Evans (1993, 2004) e Evans (2012), essa literatura também possui dificuldade em diferenciar o crescimento econômico proveniente dos incentivos ao investimento privado daquele associado à Capacidade transformativa. O corrente estudo também inova ao construir indicadores que diferenciam as políticas produtivas da construção de arenas de diálogo com a sociedade. 
Finalmente, a literatura de capacidade transformativa se limita à estudos nacionais e carece de estudos com foco regional (Amsden, 2001; Boschi, 2007, 2013; Cerqueira, 2015; Gomes, 2016; Jaguaribe, 2015; Santana, 2015; Pires e Gomide, 2016; Stein, 2016; Grin et al., 2018). Especificamente para o caso brasileiro, a importância dos municípios se intensificou com a redemocratização, descentralização e maior autonomia dos governos locais a partir da década de 1990 (Abrucio e Franzese, 2007). A maior autonomia e a descentralização das atribuições resultaram em maior espaço para a construção de capacidades estatais nos municípios, sendo necessários estudos que desenvolvam indicadores capazes de mensurar essas capacidades em âmbito municipal (Barreto et al., 2018; Gomide et al., 2014).

Diante dessas observações, as perguntas de pesquisa podem ser definidas conforme segue: qual o grau de desenvolvimento das Capacidades transformativas possuídas pelos municípios brasileiros? A diferenciação entre políticas de incentivo produtivo, Instituições e Capacidade transformativa é factível e explica o crescimento econômico municipal? Esse estudo buscar respostas para essas perguntas e caracteriza as Capacidades transformativas possuídas pelos municípios brasileiros.

\section{Métodos e procedimentos}

\subsection{Dados utilizados}

O Guadro 1 compila as variáveis discriminadas de acordo com a sigla, a fonte, o ano e a dimensão mensurada. Nove variáveis são utilizadas para extrair dois fatores que identificam a capacidade do Estado de realizar políticas produtivas:

1. APL: identifica a existência de um "aglomerado de empresas, localizadas em um mesmo território, que apresentam especialização produtiva e mantêm vínculos de articulação, interação, cooperação e aprendizagem entre si e com outros atores locais" (IBGE, 2016, p. 44). A presença de organização e alinhamento político, voltado para a produção de bens e serviços pelos quais o município já é reconhecido, decorre da capacidade de organização e coordenação local e possivelmente contribui para o crescimento econômico local;

2. Incentivo: existência em âmbito municipal de políticas de concessão de benefícios fiscais (isenção do IPTU, redução do IPTU, Isenção do ISS ou isenção de outras taxas) e não fiscais (cessão ou doação de terrenos) para atrair empresas. Os "governos municipais têm buscado influenciar a decisão de onde serão implantados novos empreendimentos, visando promover o deslocamento de um investimento para dentro de seus territórios" (IBGE, 2016, p. 24). A instalação de empresas aumenta a oferta de empregos e a demanda, o que atrai novas atividades e gera receita própria e crescimento econômico.

3. Restrição: presença de ferramentas que dificultam a instalação de novos empreendimentos que não são de interesse do município ou que são prejudiciais 
Quadro 1. Variáveis utilizadas discriminadas por sigla e fonte

\begin{tabular}{|c|c|c|c|}
\hline Sigla & Variável & Fonte & Discriminação \\
\hline APL & Arranjo Produtivo Local (APL) & Munic, 2015 & Pol. produtivas \\
\hline Incentivo & Incentivo à empreendimentos & Munic, 2015 & Pol. produtivas \\
\hline Restrição & Restrição à empreendimento & Munic, 2015 & Pol. produtivas \\
\hline Inclusão & Inclusão produtiva & Munic, 2018 & Pol. produtivas \\
\hline Rural & Inclusão produtiva rural & Munic, 2018 & Pol. produtivas \\
\hline Urbana & Inclusão produtiva urbana & Munic, 2018 & Pol. produtivas \\
\hline Qualificação & Qualificação profissional & Munic, 2018 & Pol. produtivas \\
\hline Crédito & Crédito, microcrédito e seguro & Munic, 2018 & Pol. produtivas \\
\hline Renda & Geração de trabalho e renda & Munic, 2018 & Pol. produtivas \\
\hline Cons & Proporção de conselhos municipais & Munic, $2017 / 8 / 9$ & C. transformativa \\
\hline OSC & Organizações da Sociedade Civil & IPEA, 2018 & C. transformativa \\
\hline Abs & Taxa de abstenção eleitoral & TSE, 2016 & C. transformativa \\
\hline $\operatorname{Tr}$ & Îndice de transparência municipal & MPF, 2016 & C. transformativa \\
\hline Inst & Presença de regras formais & Munic, 2015-7 & Instituições \\
\hline $\mathrm{T}$ & Temperatura média anual & CPTEC, 2018 & Instituições \\
\hline Lat & Latitude geográfica municipal & IBGE & Instituições \\
\hline Est & Proporção func. estatutários & Munic, 2015 & Burocracia \\
\hline Func & Func. públicos per capita & Munic, 2015 & Burocracia \\
\hline Sup & Proporção func. Ens. superior & Munic, 2018 & Burocracia \\
\hline Pop & Número de habitantes & IBGE, 2015 & Controle \\
\hline Urb & Taxa de urbanização & IBGE, 2015 & Controle \\
\hline PIB & Valor adicionado bruto/população & IBGE, 2015 & Var. explicada ${ }^{1}$ \\
\hline
\end{tabular}

Fonte: Elaboração própria, ${ }^{1}$ Secretaria da Fazenda, Variável explicada

a qualidade de vida da população (IBGE, 2016). Evidencia a capacidade de articulação política e de regulação local decorrente da priorização de objetivos e atividades, o que pode favorecer o crescimento econômico ao reforçar as atividades que exibem maior potencial produtivo local;

4. Inclusão: identifica se o município possui Ações, programas ou projetos de Inclusão produtiva para a geração de trabalho e renda. Essas políticas promovem "a aquisição de habilidades e conhecimentos necessários para a inserção no mundo do trabalho" e proporcionam aos indivíduos "em situação de vulnerabilidade econômica e social o acesso a mecanismos que possibilitem sua inserção na produção de bens e serviços", o que se traduz em oportunidades de trabalho e renda (IBGE, 2019, p. 72). Essa variável verifica se a adoção de políticas de inclusão produtiva contribui para o crescimento da renda, sendo o sinal esperado positivo. Isto é, os municípios que adotam políticas de inclusão produtiva conseguem obter uma renda mais elevada.

5. Rural: mensura a adoção de Ações, programas ou projetos voltados para "for- 
talecer as atividades realizadas pelas famílias da agricultura familiar em vulnerabilidade social, de forma a aumentar a sua capacidade produtiva e a entrada de seus produtos nos mercados consumidores por meio de orientação e acompanhamento técnico" (IBGE, 2019, p. 75). Essa variável evidencia a importância de políticas direcionadas para a qualificação da população rural, que podem se transcrever em maiores taxas de crescimento econômico ao estimular o surgimento de novos empreendimentos no meio rural e contribuir para a maior eficiência produtiva;

6. Urbana: mostra se o município adota Ações, programas ou projetos voltados para a Inclusão produtiva urbana. Ela "Reúne iniciativas de apoio a microempreendedores e a cooperativas de economia solidária, bem como de oferta de qualificação profissional e intermediação de mão de obra que visam à colocação dos beneficiários em postos de empregos formais" (IBGE, 2019, p. 76). As políticas de integração produtiva da população urbana com mais dificuldade a ajuda a se inserir no circuito produtivo, o que pode favorecer o crescimento econômico, além de estimular a diversificação da estrutura produtiva local e a integração da parcela da população que se encontra excluída;

7. Qualificação: mensura se o município possui Ações, programas ou projetos voltados para a qualificação profissional e intermediação da mão de obra. Ela demonstra a importância do investimento em capital humano direcionado para atividades com maior capacidade de geração de renda, o que pode se traduzir em maiores taxas de crescimento econômico;

8. Crédito: verifica se o município desenvolve ações, programas ou projetos de crédito, microcrédito e seguro. Segundo (IBGE, 2019, p. 77), "essas ações têm como principais objetivos ampliar o microcrédito produtivo orientado, aumentar as linhas de crédito e ampliar o apoio aos empreendimentos de economia solidária e ao cooperativismo". A hipótese testada é que essas ações oxigenam os estabelecimentos locais com recursos monetários, o que favorece a diversificação produtiva, o emprego e a renda;

9. Renda: denota a presença de Ações, programas ou projetos de inclusão produtiva para a geração de trabalho e renda em iniciativas de associativismo, cooperativismo e economia solidária. Engloba as políticas públicas direcionadas para as famílias mais carentes, o que possivelmente resulta em maiores taxas de crescimento econômico ao ativar o consumo de famílias de menor renda e elevar a demanda por novos bens e serviços locais.

A contribuição da capacidade transformativa e das Instituições para o crescimento econômico é identificada por meio das seguintes variáveis:

10. Cons: identifica a proporção de conselhos que o município possui, sendo tabulada com base na pesquisa MUNIC/IBGE 2017, 2018 e 2019, para os seguintes 
conselhos: Segurança pública; Defesa civil; Direitos Humanos; Direitos da Pessoa Idosa; Direitos da Pessoa com Deficiência; Direitos de Lésbicas, Gays, Bissexuais, Travestis e Transexuais; Igualdade Racial; Conselho Tutelar; Educação; Controle e acompanhamento social do FUNDEB; Alimentação escolar; Transporte escolar; Cultura; Preservação do Patrimônio; Saúde; Direitos da mulher e Habitação. A proporção de conselhos identifica se as gestões municipais possuem uma postura aberta ao diálogo e à elaboração de políticas em conjunto com a sociedade, o que favorece o aumento no nível de renda.

11. Tr: o Índice de transparência municipal, disponibilizado pelo Ministério Público Federal (MPF), mostra se os municípios disponibilizam informações detalhadas sobre a execução orçamentária e financeira. Ele mostra se as gestões municipais fornecem informações detalhadas aos munícipes sobre as contas públicas. Esse indicador identifica se elas são receptivas ao diálogo com a população sobre as políticas públicas realizadas e a situação financeira municipal. Ele se encontra intimamente relacionado com a presença de capacidade transformativa.

12. Inst: avalia a capacidade institucional do município. Ela mensura a proporção de legislações que o município possui em 17 áreas distintas, precisamente: plano diretor; zona especial de interesse social; zona e/ou área de especial interesse; parcelamento do solo; zoneamento ou uso e ocupação do solo; solo criado ou outorga onerosa do direito de construir; operação urbana consorciada; estudo de impacto de vizinhança; zoneamento ambiental ou zoneamento ecológico e econômico; unidade de conservação; concessão de uso especial para fins de moradia; usucapião especial de imóvel urbano; direito de superfície; regularização fundiária; legitimação de posse; estudo prévio de impacto ambiental; permissão de atividades extrativas minerais. Essa variável mensura a capacidade das gestões municipais em desenvolver regras formais responsáveis por reduzir a incerteza e garantir os direitos de propriedade e a proteção dos contratos.

Três variáveis identificam se o município possui uma burocracia estatal qualificada, contratada a partir de critérios meritocráticos.

13. Est: identifica a proporção de funcionários estatutários na administração direta, sendo extraída da base de dados Munic/IBGE para o ano de 2015. Ela é adicionada para verificar se a presença de uma burocracia municipal mais insulada, contratada a partir de critérios rigorosos, favorece o crescimento econômico, sendo o sinal esperado positivo. Conforme destacado por (Weber, 1994), a presença de uma burocracia insulada possibilita que o setor público desenhe políticas ser perecer diante da pressão do setor privado.

14. Fun: mensura o tamanho da máquina administrativa local, sendo obtida mediante a divisão do número de funcionários da administração direta pela população total do município. Essa variável testa se a presença de uma máquina administrativa maior afeta positivamente as taxas de crescimento econômico (Weber, 1994). 
15. Sup: é o número de funcionários públicos da administração direta com ensino superior ou pós-graduação dividido pelo total de funcionários públicos na administração direta. Essa variável testa o argumento weberiano de que a maior qualificação da burocracia local contribui para o crescimento econômico (Rauch e Evans, 2000; Evans, 2004).

Duas variáveis de controle, amplamente utilizadas pela literatura de Instituições, são adicionadas para identificar os demais fatores que influenciam na taxa de crescimento econômico municipal:

Pop: o número de habitantes possuído pelo município identifica se municípios maiores exibem taxas mais elevadas de crescimento econômico, sendo obtida da base de dados do Instituto Brasileiro de Geografia e Estatística (IBGE);

16. Urb: é a população urbana dividida pela população total do município, verifica se a urbanização resulta em maior crescimento da renda, sendo extraída da base de dados do IBGE.

Como a elaboração de políticas públicas depende do montante de arrecadação, determinado pelo nível de renda, as estimações estão sujeitas aos problemas de endogeneidade e de causalidade reversa. Assim, os dados acima são utilizados para estimar cinco modelos econométricos iniciais, nos quais as variáveis Cons e Transp mensuram a Capacidade transformativa e a variável Inst, as Instituições. Posteriormente, cinco modelos adicionais são estimados com as variáveis $O S C s$ e Abs empregadas como instrumentos para a Capacidade transformativa e as variáveis Lat e Temp, como instrumentos para Instituições, sendo essas variáveis definidas a seguir:

17. OSC: a corrupção mina a confiança dos munícipes no Estado, o que afeta a disposição a pagar impostos, apoiar a extensão da autoridade do Estado e se engajar em atividades coletivas. Regiões com baixa corrupção possuem maior participação da sociedade na elaboração de políticas públicas e altos níveis de capital social (Putnam, 1993; Fortin-Rittberger, 2014; Charron e Rothstein, 2014; Charron et al., 2017). O logaritmo do número de Organizações da Sociedade Civil (OSCs), tabulado pelo Instituto de Pesquisa Econômica Aplicada (IPEA), é utilizado para medir o capital social dos municípios. Conforme demonstrados pela literatura, essa variável se encontra diretamente relacionada com a Capacidade transformativa.

18. Abs: a construção de arenas de diálogo do Estado com a sociedade resulta em maior confiança no Estado, o que eleva o nivel de participação cívica (Charron et al., 2017). A participação cívica é capturada por meio de taxas de abstenção eleitoral, disponibilizada pelo Tribunal Superior Eleitoral para o ano de 2016, sendo esperado uma relação negativa com o crescimento econômico.

19. T: a temperatura média anual, extraída do Centro de Previsão de Tempo e Estudos Climáticos (CPTEC/INPE) para o ano de 2015, é utilizada como instrumento 
de controle para o problema de endogeneidade associado à capacidade institucional, dada a sua relação positiva com a colonização europeia e a presença de instituições mais favoráveis ao crescimento econômico (Acemoglu e Robinson, 2012).

20. Lat: semelhante à temperatura, essa variável é utilizada pela literatura institucional como instrumento para as Instituições, sendo extraída da base de dados do IBGE. O PIB per capita, o tamanho do município e a densidade demográfica são expressos na forma logarítmica, sendo os dados de todas as variáveis levantados para 4.359 municípios brasileiros.

\subsection{Procedimentos estatísticos e econométricos}

A análise fatorial parte do pressuposto de que as variáveis que se encontram no mesmo fator mensuram o mesmo fenômeno, sendo essa a fonte da variação semelhante entre elas. De modo que a correlação elevada entre as variáveis se deve a um fator (fenômeno) não observável diretamente, subjacente a essas variáveis. Assim, ela identifica esses fatores, simplifica estruturas complexas de dados e explica de forma lógica a estrutura de correlações implícita no conjunto de dados.

Cabe salientar que as variações exibidas por uma variável podem ser mensuradas por mais de um fator, conforme segue:

$$
X_{i}=\alpha_{1} F_{1}+\alpha_{2} F_{2}+\ldots+\alpha_{n} F_{n}+\epsilon_{i}
$$

em que $X_{i}$ são as variáveis padronizadas; $\alpha_{i}$, as cargas fatoriais; $F_{i}$, os fatores comuns e $\epsilon_{i}$, o termo de erro.

Os fatores também podem ser estimados como uma combinação linear das variáveis para um $j-$ simo fator:

$$
F_{j}=\lambda_{1} X_{1}+\lambda_{2} X_{2}+\ldots+\lambda_{n} X_{n}
$$

em que $X_{i}$ são as variáveis observáveis e $\lambda_{i}$ são os escores fatoriais. De forma resumida, a análise fatorial é realizada mediante o seguinte procedimento: (i) calcula-se a matriz de correlação de todas as variáveis; (ii) aplica-se os testes de esfericidade de Bartlett e de Kaiser-Meyer-Olkin (KMO) para identificar se as variáveis que compõem a base de dados são interdependentes; (iii) extraem-se os fatores, por meio da análise de componentes principais; (iv) rotaciona-se os fatores extraídos pelo método Varimax para evitar a ocorrência de uma variável com altas cargas fatoriais para vários fatores; e, (v) identifica-se os escores fatoriais (Corrar et al., 2009). 
Após a extração dos fatores se constrói a matriz de pesos espaciais, que identifica os efeitos de contiguidade e de vizinhança presentes nos dados em estudo. A literatura especializada utiliza diferentes medidas para a vizinhança geográfica, sendo as mais comuns as matrizes de peso espacial do tipo rainha, torre e $k$ vizinhos mais próximos (Almeida, 2012). A matriz torre delimita a vizinhança pela fronteira física com extensão diferente de zero entre as regiões. A matriz rainha define a vizinhança como equivalente à fronteira física e aos vértices contíguos. Já a matriz de $k$ vizinhos mais próximos considera que a vizinhança é dada por:

$$
\begin{gathered}
w_{i j}=0 \text { se } i=j \\
w_{i j}=1 \text { se } d_{i j} \leq D_{i}(k) \quad \text { e } \frac{W_{i j}(k)}{\sum W_{i j}(k)} \text { para } k=1,2, \ldots, n \\
w_{i j}=0, \text { se } d_{i j}>D_{i}(k)
\end{gathered}
$$

em que $d_{i j}$ é a distância entre os municípios $i$ e $j$ e $D_{i}(k)$ é a distância máxima da vizinhança do município $i$ e $W$ é o peso espacial do município.

Com a matriz de vizinhança em mãos se calculam as correlações. O coeficiente $I$ de Moran global mensura a autocorrelação espacial, sendo denotado por (Almeida, 2012):

$$
I=\frac{n \quad z^{\prime} W z}{S \quad z^{\prime} z}
$$

em que $n$ é o número de municípios; $z$, o valor assumido pela variável para o município $i$; e $W$, a matriz de proximidade espacial. A matriz de pesos espaciais é normalizada, $I=\frac{z^{\prime} W z}{z^{\prime} z}$, para testar a hipótese nula de aleatoriedade espacial contra a hipótese alternativa de que $z$ possui dependência espacial. Valores entre 0 e 1 evidenciam autocorrelação espacial direta e valores entre 0 e -1, autocorrelação espacial inversa.

Diferente do coeficiente $I$ de Moran global, o índice $I_{i}$ de Moran local (Local Indicator of Spatial Association - LISA), identifica as relações locais existentes entre os municípios. Esse índice decompõem o indicador global em quatro categorias: AltoAlto (High-High) - o município possui valor elevado para a variável $x$ e é rodeado por municípios que também possuem valor elevado para essa variável; Baixo-Baixo (LowLow) - o município exibe valor baixo para $x$ e se encontra cercado por municípios que apresentam baixo valor para essa variável; Alto-Baixo (High-Low) - o município possui valor elevado para $x$ e se encontra cercado por municípios com baixo valor 
para essa variável; Baixo-Alto (Low-High) - o município exibe baixo valor para $x$ e se encontra cercado por municípios com valor elevado para essa variável. O coeficiente $I_{i}$ de Moran local, obtido para a variável padronizada, $z$, é denotado por:

$$
I_{i}=z_{i} \sum_{i=1}^{I} w_{i j} z_{i}
$$

sendo esse coeficiente calculado apenas para os vizinhos do município $i$ que se encontram na matriz de pesos espaciais. Cabe destacar que o somatório dos coeficientes locais é igual ao valor encontrado para o coeficiente global, isto é:

$$
\sum_{i} I_{i}=\sum_{i} z_{i} \sum w_{i j} z_{j}=\sum_{i} \sum_{j} w_{i j} z_{i} z_{j}
$$

sendo possível se escrever o índice I de Moran local como (Anselin, 1995):

$$
I_{i}=\frac{n}{s_{0}} \frac{\sum_{i} \sum_{j} w_{i j} z_{i} z_{j}}{\sum_{i=j}^{n} z_{i}^{2}}=\frac{\sum_{j} I_{i}^{2}}{S_{0} \sum_{i} \frac{z_{i}^{2}}{n}}
$$

Após verificar se os dados exibem associação espacial, o próximo passo consiste em estimar o modelo por Mínimos Quadrados Ordinários (MQO):

$$
y=X \beta+\epsilon,
$$

sendo $y$, a variável dependente, no caso o logaritmo do $P I B$ per capita para o ano de 2015; $X$ a matriz de variáveis independentes, $\beta$ o vetor de parâmetros estimados e $\epsilon$ o termo de erro.

A literatura de modelos espaciais apresenta diferentes abordagens que identificam os processos de transbordamento espaciais. Entre os modelos mais utilizados se destacam o Espacial defasado X (Spatially Lagged X - SLX):

$$
y=X \beta+W X \theta+\epsilon,
$$

com defasagem espacial na variável explicativa. Defasagem espacial (Spatial Lag - 
$S A R):$

$$
y=\rho W y+X \beta+\epsilon,
$$

no qual a variável dependente do município i está correlacionada com a variável dependente do município $j$, sendo $|\rho|<1$.

Erro Espacial (Spatial Error Model - SEM):

$$
\begin{gathered}
y=X \beta+u, \\
u=\lambda W u+\epsilon,
\end{gathered}
$$

em que a dependência espacial se manifesta apenas no padrão do erro aleatório entre os municípios vizinhos, sendo o efeito de transbordamento identificado pelo parâmetro $\lambda$, dada a restrição $|\lambda|<1$.

Espacial de Durbin:

$$
y=\rho W y+X \beta+W X \theta+\epsilon,
$$

sendo tanto a variável dependente, $\rho W y$, quanto as variáveis explicativas, $W X 0$, exibem efeito espacial, e Durbin de Erro autorregressivo espacial (SDEM):

$$
y=X \beta+W X \theta+u, u=\lambda W u+\epsilon
$$

em que a variável explicativa, $W X \theta$, e o termo de erro, $\lambda W u$, apresentam autocorrelação espacial.

O teste de razão de máxima verossimilhança identifica se os modelos aninhados $S L X, S E M$ e $M Q O$ e $S L X, S A R$ e $M Q O$ possuem melhor ajuste que os modelos $S D M$ e $S D E M$, respectivamente. Para isso, dada uma amostra $y$ de tamanho $n$, com média $\mu$ e variância $\sigma^{2}$, a função de máxima verossimilhança é escrita como:

$$
L(\mu)=L_{n}\left(\mu \mid y \sigma^{2}\right)=-n \log (\sigma \sqrt{2} \pi)-\frac{1}{2 \sigma^{2}} \sum_{i=1}^{n}\left(y_{i}-\mu\right)^{2},
$$

sendo testada a hipótese $H 0: \mu=0$, por meio da diferença nas funções de log máxima verossimilhança: $L(\mu)-L\left(\mu_{0}\right)=\left(\frac{\overline{y_{n}}-\mu}{\sigma \sqrt{n}}\right)^{2}$, que possui distribuição $\chi^{2}$ (LeSage, 2014). 


\section{Resultados encontrados}

\subsection{Estatísticas descritivas}

As estatísticas descritivas, Tabela 1, mostram que 62\% dos municípios brasileiros possuem Mecanismos de incentivo à implantação de empreendimento em 2018. Desses, 28\% recorrem à redução e 40\% à isenção de IPTU; 29\% isentam os empreendedores de ISSQN e 35\% isentam do pagamento de taxas; $43 \%$ cedem terrenos e $40 \%$ doam terrenos. Entre os empreendimentos beneficiados pelos mecanismos de incentivo, $71 \%$ são estabelecimentos industriais; $62 \%$, comerciais e de serviços; $20 \%$, turismo, esporte e lazer e 24\%, agropecuário. Ademais, 25\% dos municípios restringem a implantação de empreendimentos; 88\% desses utilizam a legislação para esse fim e $17 \%$ cobram tributos. Em 51\% dos municípios esses mecanismos de restrição incidem sobre a indústria de transformação; em 34\%, sobre a indústria extrativa; em $35 \%$, sobre estabelecimentos comerciais e serviços; $13 \%$, turismo, esporte e lazer e $76 \%$, empreendimentos com impacto ambiental.

Tabela 1. Percentual dos municípios que possuem mecanismos de incentivo e restrição à implantação de empreendimentos, 2015

\begin{tabular}{lllllr}
\hline \hline Mecanismo & $\%$ & Mecanismos & $\%$ & Mecanismos & $\%$ \\
\hline Incentivo & $62 \%$ & Restrição & $25 \%$ & Qual. profissional & $93 \%$ \\
Redução IPTU & $28 \%$ & Legislação & $88 \%$ & Intermediação & $55 \%$ \\
Isenção IPTU & $40 \%$ & Tributação & $17 \%$ & Mobilização & $87 \%$ \\
Isenção ISSQN & $29 \%$ & Indústria & $51 \%$ & Fomento & $64 \%$ \\
Isenção taxas & $35 \%$ & Extrativa & $34 \%$ & Assistência & $58 \%$ \\
Cessão terrenos & $43 \%$ & Comercial & $35 \%$ & Incubação & $25 \%$ \\
Doação terrenos & $40 \%$ & Turismo & $13 \%$ & Artesanato & $83 \%$ \\
Industrial & $71 \%$ & Impacto ambiental & $76 \%$ & Doação & $33 \%$ \\
Comercial & $62 \%$ & Inclusão produtiva urbana & $48 \%$ & Crédito & $37 \%$ \\
Turismo & $20 \%$ & Urbana & $69 \%$ & Trabalho & $60 \%$ \\
Agropecuário & $24 \%$ & Gual. profissional e int. & $64 \%$ & - & - \\
\hline \hline
\end{tabular}

Fonte: Adaptado de Munic/IBGE $(2015,2018)$

Ademais, 48\% dos municípios possuem políticas de qualificação e de inclusão produtiva urbana. Desses, 69\% possuem ações de fomento aos empreendimentos individuais urbanos; 64\%, qualificação profissional e intermediação da mão de obra; 93\%, qualificação profissional; 55\%, intermediação da mão de obra e $87 \%$, mobilização para qualificação profissional. A pesquisa Munic também mostra que $64 \%$ dos municípios possuem políticas de fomento para empreendimentos coletivos urbanos (Associativismo, Cooperativismo, Economia Solidária, entre outros); destes, 58\% possuem ações de assistência técnico-gerencial; 25\% incubam empreendimentos; $83 \%$ fomentam o artesanato e 33\%, doam equipamentos para o trabalho. Ademais, $37 \%$ dos 
municípios possuem programas de crédito, microcrédito e seguro e $60 \%$, de trabalho e renda.

\subsection{Análise fatorial}

Os resultados encontrados para os testes de Kaiser-Meyer-Olkin e Bartlett, 0,831 e 6.460,858, respectivamente, evidenciam o elevado poder de explicação dos fatores extraídos acerca da variabilidade na massa de dados. As variáveis Inclusão produtiva, Qualificação, Crédito e Renda, Tabela 2, ficam no mesmo fator, o qual explica 36,248\% da variância total nos dados. Como esse fator identifica políticas voltadas para a inclusão produtiva, ele recebe o nome de Inclusão produtiva.

Tabela 2. Análise fatorial, componentes rotacionados

\begin{tabular}{llllll}
\hline \hline Variável & Fator 1 & Variável & Fator 1 & Variável & Fator 2 \\
\hline Inclusão & 0,750 & Urbana & 0,721 & Incentivo & 0,771 \\
Rural & 0,646 & Crédito & 0,510 & Restrição & 0,787 \\
Gualificação & 0,732 & Renda & 0,772 & & \\
\hline \hline
\end{tabular}

Fonte: Elaboração própria.

O segundo fator, por sua vez, é composto pelas variáveis Incentivo e Restrição à implantação de empreendimento e explica 15,905\% da variância total nos dados, sendo nomeado Implantação de empreendimentos.

\subsection{Correlação espacial}

A Tabela 3 consolida a correlação espacial compilada com base nas matrizes de contiguidade Rainha e Torre, para ordens de um (1), dois (2) e três (3), e Knn, para os quatro (4), oito (8), doze (12) e vinte (20) vizinhos mais próximos. As correlações mais elevadas são obtidas para a matriz de vizinhança $K n n(4)$, para as variáveis $P I B, A b s$, Transp, Cons e Inst, sendo de 0,639, 0,351, 0,318, 0,226 e 0,200, respectivamente. Em contrapartida, as variáveis que exibem menor correlação espacial são Fator 1, $O S C$ e Fator 2, com correlações de 0,084, 0,133 e 0,139, respectivamente. Os baixos resultados das correlações espaciais evidenciam a baixa imitação entre os municípios. De modo que as políticas produtivas, a capacidade transformativa e as instituições não são intensamente copiadas pelos municípios vizinhos.

O Mapa 1, painel central, mostra que as Instituições assumem valor superior à 0,632 para 861 municípios, entre 0,368 e 0,632 para 1,260 municípios; entre 0,158 e 0,368 para 1.159 municípios e inferior à 0,158 para 2.288 municípios. Os municípios 
Tabela 3. Resultados obtidos para o coeficiente I de Moran de correlação espacial global, 2015 e 2018

\begin{tabular}{lllllllllll}
\hline \hline & $\mathrm{R}^{1}(1)$ & $\mathrm{R}(2)$ & $\mathrm{R}(3)$ & $\mathrm{T}^{2}(1)$ & $\mathrm{T}(2)$ & $\mathrm{T}(3)$ & $\mathrm{K}^{3}(4)$ & $\mathrm{K}(8)$ & $\mathrm{K}(12)$ & $\mathrm{K}(20)$ \\
\hline PIB & 0,532 & 0,515 & 0,502 & 0,533 & 0,507 & 0,491 & 0,639 & 0,584 & 0,564 & 0,542 \\
Fator 1 & 0,082 & 0,048 & 0,034 & 0,083 & 0,048 & 0,054 & 0,084 & 0,082 & 0,073 & 0,064 \\
Fator 2 & 0,133 & 0,107 & 0,085 & 0,133 & 0,107 & 0,099 & 0,139 & 0,129 & 0,123 & 0,115 \\
Cons & 0,208 & 0,192 & 0,190 & 0,209 & 0,192 & 0,191 & 0,226 & 0,213 & 0,206 & 207 \\
Transp & 0,310 & 0,299 & 0,284 & 0,309 & 0,289 & 0,285 & 0,318 & 0,314 & 0,313 & 0,308 \\
OSC & 0,129 & 0,089 & 0,083 & 0,129 & 0,089 & 0,084 & 0,133 & 0,123 & 0,116 & 0,112 \\
Inst & 0,198 & 0,180 & 0,163 & 0,197 & 0,179 & 0,164 & 0,200 & 0,197 & 0,192 & 0,188 \\
Abs & 0,337 & 0,277 & 0,250 & 0,338 & 0,278 & 0,250 & 0,351 & 0,330 & 0,319 & 0,300 \\
\hline \hline
\end{tabular}

Fonte: Elaboração própria. Nota: ${ }^{1}$ Rainha, ${ }^{2}$ Torre, ${ }^{3}$ Knn.

das Regiões Sul e Sudeste são os que possuem maior capacidade institucional. No entanto, o indicador de capacidade institucional exibe valores inferiores ao indicador de Capacidade transformativa, pois 39\% dos municipios possuem valor superior à 0,5 para esse indicador, ao passo que apenas $24 \%$ possuem valor superior à 0,5 para Instituições. Assim, os municípios carecem de legislações que zelem pelos diretos de propriedade e que normatizem as interações econômicas.

A Figura 1, painel à direita, consolida os dados do PIB, precisamente, $579 \mathrm{mu}$ nicípios possuem valor, em logaritmo, superior à 10,510 para essa variável; 1.483, valor entre 9,850 e 10,$510 ; 1.613$, entre 9,220 e 9,850 e 1.893 , inferior à 9,220 . As Regiões Sul, Sudeste e Centro-Oeste são as que apresentam valores mais elevados. Já o Mapa 1, painel à esquerda, mostra que 720 municípios possuem valor superior à 0,647 para Conselhos, seguidos por 1.444 municípios com valor entre 0,529 e 0,647 para essa variável, 2.147 municípios com valor entre 0,412 e 0,539 e 1.257 municípios com valor inferior à 0,412 . Os municípios com maior capacidade transformativa se encontram nas Regiões Sul e Sudeste do país.

Os resultados encontrados para o coeficiente $I_{i}$ de Moran local (LISA), Figura 2, com base na matriz de ponderações espaciais Rainha (1), corroboram esses resultados. Para a variável Conselhos foram encontrados 309 agrupamentos do tipo AltaAlta, 520 agrupamentos Baixa-Baixa; 287, Baixa-Alta e 106, Alta-Baixa. Destarte, se observa a formação de agrupamentos locais, com destaque para o elevado número de agrupamentos Baixa-Baixa presentes nas Regiões Norte e Nordeste. Para a variável Instituições foram encontrados 490 agrupamentos Alta-Alta, 492 Baixa-Baixa; 204 Baixa-Alta e 136 Alta-Baixa. Observa-se a formação de grandes agrupamentos de municípios com correlação no Sul, principalmente nos estados de Santa Catarina e Paraná, e no Norte do país, no Amazonas, e de municípios com correlação Baixa- 
Baixa, na região Nordeste.

Figura 1. Resultados encontrados para o coeficiente I de Moran Local Univariado, 2015 e 2018

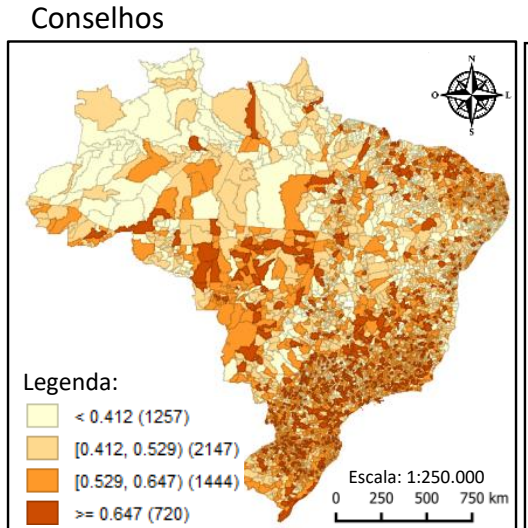

Instituições

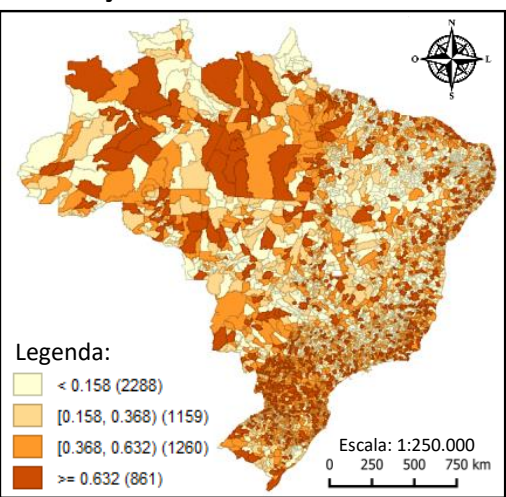

PIB

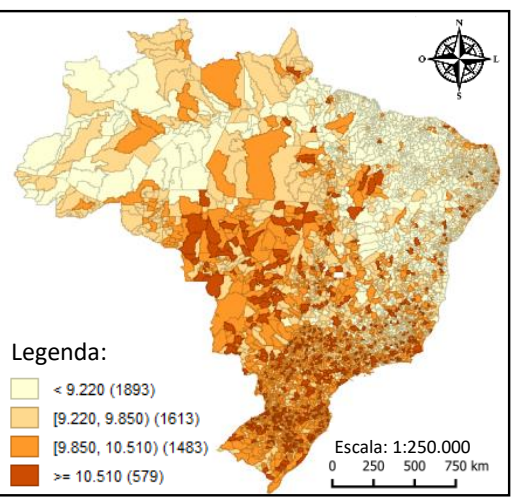

Fonte: Adaptado de Munic/IBGE (2015, 2018) e IBGE (2015).

Figura 2. Resultados encontrados para o coeficiente I de Moran Local Univariado, 2015 e 2018

Conselhos

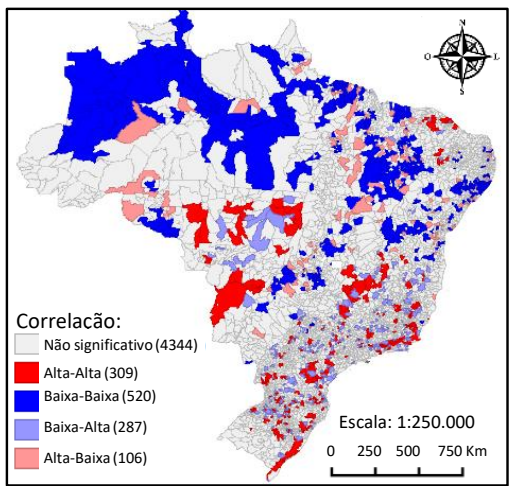

Transparência

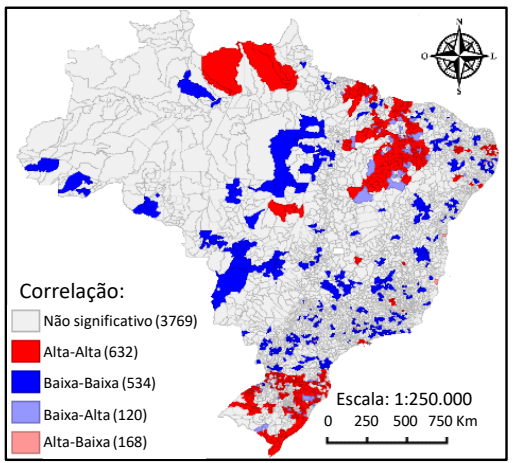

Instituições

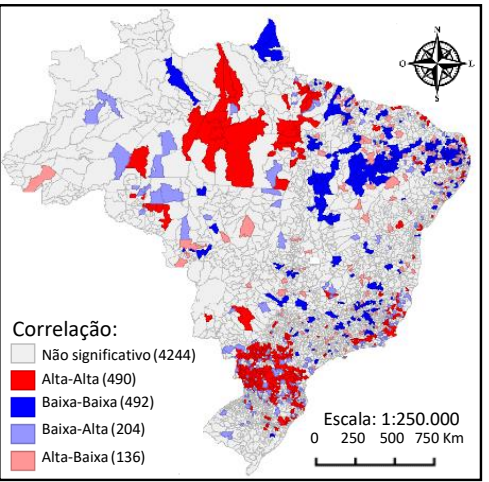

Abstenção

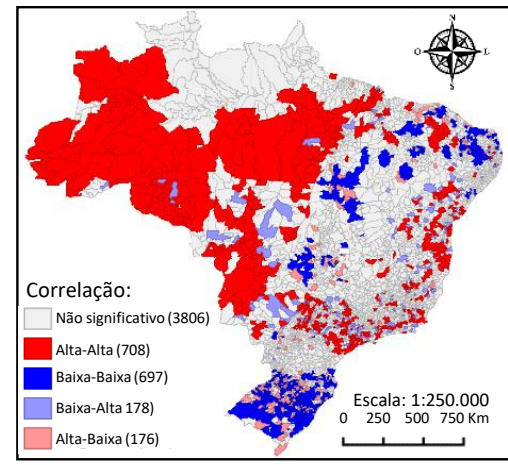

PIB

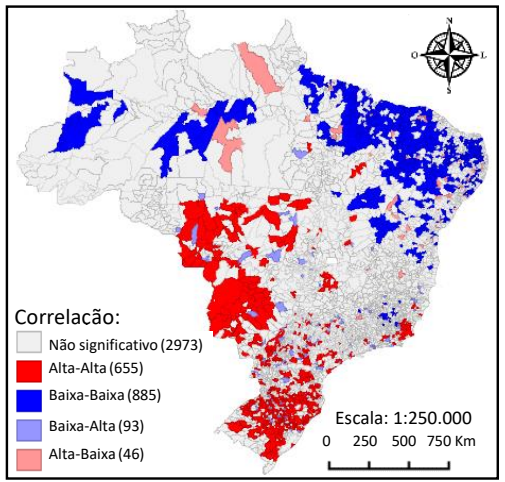

Fator 2

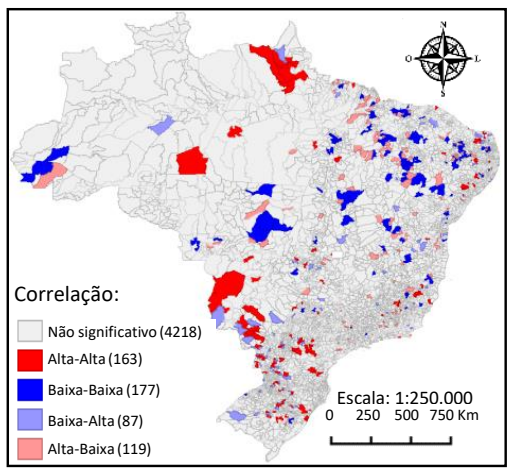

Fonte: Adaptado de Munic/IBGE $(2015,2018)$ e IBGE (2015).

O PIB per capita exibe menor número de municípios com correlação local não significativa, 2.973 municípios, sendo a variável com maior persistência espacial. Observam-se dois grandes agrupamentos de municípios com correlação Alta-Alta nas Regiões Sul e Centro-Oeste do país, e de pequenos agrupamentos na Região Sudeste. 
Também se verifica um grande agrupamento do tipo Baixa-Baixa na Região Nordeste do país e agrupamentos locais na Região Norte. Já a Transparência (Abstenção) exibe correlação local Alta-Alta (Baixa-Baixa) para os estados de Rio Grande do Sul e Santa Catarina e Baixa-Baixa (Alta-Alta) para um agrupamento no Norte-Nordeste (CentoOeste-Norte). Não se observa a formação de grandes agrupamentos para o Fator 2.

\subsection{Regressões estimadas}

O teste de Razão de máxima verossimilhança mostra que o modelo $S D E M$ apresenta melhor especificação do que os modelos $S E M, S L X$ e $M Q O$, respectivamente, Tabela 4, tanto para a configuração sem as variáveis instrumentais quanto para a configuração com as variáveis instrumentais. Os testes realizados para o modelo $S D M$ também evidenciam que esse modelo exibe melhor especificação do que os modelos $S L X, S A R$ e $M Q O$ para ambas as configurações.

Tabela 4. Resultados encontrados para os testes de razão de máxima verossimilhança para o modelo com variáveis originais (instrumentais)

\begin{tabular}{llc|llr}
\hline \hline Teste & Resultado & P-valor & Teste & Resultado & P-valor \\
\hline SDEM contra SEM & $\begin{array}{l}321,52 \\
(357,51)\end{array}$ & 0,000 & SDM contra SLX & $\begin{array}{l}327,74 \\
(49,434)\end{array}$ & 0,000 \\
SDEM contra SLX & $\begin{array}{l}658,49 \\
(406,08)\end{array}$ & 0,000 & SDM contra SAR & $571,6(572,42)$ & 0,000 \\
SDEM contra MQO & $\begin{array}{l}741,28 \\
(458,36)\end{array}$ & 0,000 & SDM contra MQO & $654,39(624,7)$ & 0,000 \\
\hline \hline
\end{tabular}

Fonte: Os autores, todos os testes retornam pvalor de 0,000.

Os resultados encontrados para as regressões estimadas, Tabela 5, corroboram esses testes, sendo o coeficiente adicionado para a variável dependente defasada significativo ao nível de confiança de 99\%. Com efeito, o aumento do PIB per capita de um município vizinho em $1 \%$ resulta em aumento de $0,076 \%$ e $0,342 \%$, respectivamente, na taxa de crescimento do $P I B$ per capita para os modelos $S A R$ e $S D M$. Já os modelos $S E M$ e $S D E M$ indicam que um choque estocástico de $1 \%$ em um município vizinho resulta em aumento de 0,623\% e 0,463\%, respectivamente, na taxa de crescimento da renda. Esse resultado mostra que as atividades produtivas tendem a se concentrar em locais específicos e influenciar positivamente o nível de renda dos municípios vizinhos, sendo a renda influenciada por spillovers espaciais provenientes da transferência de conhecimentos e de tecnologia e por externalidades derivadas dos municípios vizinhos (Arbia et al., 2010; Leivas et al., 2015; Marshall, 1920). 


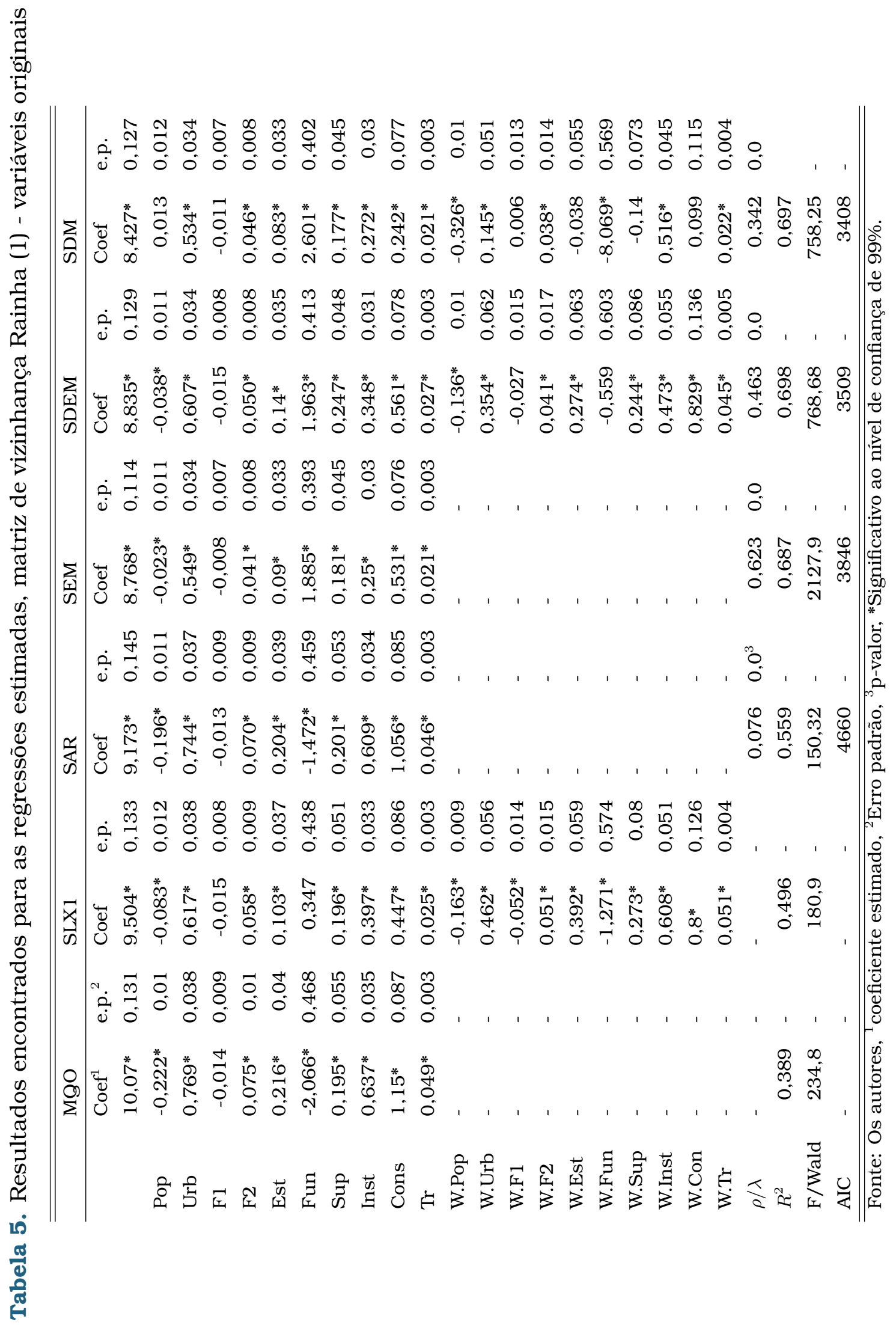


Os coeficientes estimados para o logaritmo do número de habitantes, Pop, são estatisticamente significativos e negativos para todas as regressões ao nível de confiança de 99\%, exceto para o modelo $S D M$ em nível. Esses resultados indicam que os municípios maiores exibem menores taxas de crescimento econômico do que os municípios com menos habitantes. A taxa de urbanização, Urb, em contrapartida, exibe coeficiente significativo ao nivel de confiança de 99\%. Ela corrobora o argumento de que a maior concentração da população no mesmo local gera externalidades jacobianas que beneficiam tanto o município quanto os municípios vizinhos (Arbia et al., 2010; Leivas et al., 2015). A proximidade entre as pessoas possibilita o surgimento de serviços e atividades complementares que contribuem para que municípios próximos entre si elevem o seu nível de renda per capita em detrimento de municípios com menores níveis de urbanização (Jacobs, 2016).

Dentre as variáveis que identificam a presença de políticas de intervenção no domínio produtivo, o Fator 1, Inclusão produtiva, não é significativo, exceto para o coeficiente defasado do modelo $S L X$, com sinal negativo. Esse fator mensura as políticas de inclusão produtiva que possuem como objetivo promover maior igualdade social e não necessariamente taxas mais elevadas de crescimento econômico. Essas políticas provavelmente resultam em melhores indicadores de desenvolvimento econômico e não em maiores taxas de crescimento da renda per capita, sendo necessários estudos adicionais que avaliem os efeitos dessas políticas sobre indicadores de desenvolvimento humano e social.

Os coeficientes estimados para o Fator 2, Implantação de empreendimentos, são significativos ao nível de confiança de $99 \%$ para todos os modelos estimados. Esses resultados corroboram a literatura de políticas de desenvolvimento regional, o Estado consegue utilizar os instrumentos a sua disposição para coordenar os investimentos privados e os direcionar para atividades que geram maior crescimento econômico (Suzigan e Furtado, 2006; Almeida, 2009; Cano e Silva, 2010; Mazzucato, 2014; Suzigan, 2017). Os coeficientes defasados espacialmente também são significativos e mostram que a adoção de políticas de incentivo/restrição ao surgimento de novos empreendimentos em municípios vizinhos contribui para o aumento no PIB per capita. Essas políticas geram importantes externalidades marshallianas, provenientes da concentração de atividades produtivas semelhantes na região, o que beneficia os municípios vizinhos (Marshall, 1920).

A variável Instituições também apresenta coeficientes com sinal positivo, sendo significativa ao nível de confiança de 99\%. Ela evidencia a importância do Estado como responsável por garantir um ambiente econômico mais estável e favorável aos investimentos. A presença de legislações e regras claras, que normatizam a sociedade e garantem melhores direitos de propriedade e o respeito aos contratos, reduz comportamentos oportunistas e estimula os investimentos privados, o que resulta em taxas mais elevadas de crescimento da renda (North et al., 1990; Williamson e Masten, 1999; Hodgson, 2006, 2007; Acemoglu e Robinson, 2012). 
Já as variáveis weberianas, Est, Fun e Sup, adicionadas para mensurar a qualidade da burocracia estatal, são estatisticamente significativas. O logaritmo do número de funcionários na administração direta, Fun, é a única exceção, não sendo significativo para o modelo $S L X$. Esses resultados corroboram os argumentos de Evans et al. (1985), Evans (1993); Weber (1994) e Evans (2012), a presença de uma burocracia weberiana autônoma, qualificada e insulada reduz a pressão de interesses organizados sobre a administração municipal, o que resulta em menor cooptação (Acemoglu e Robinson, 2012), maior liberdade e maior capacidade de desenho e implementação de políticas públicas favoráveis ao crescimento econômico.

As defasagens espaciais também são significativas, exceto Sup e Est para o modelo $S D M$ e Fun para o modelo $S L X$. A presença de burocracias estatais insuladas, Est, e qualificadas, Sup, contribui para o crescimento econômico dos municípios vizinhos (Gerschenkron, 1968; Johnson, 1982; Weber, 1994; Evans et al., 1985; Evans, 2012; Tilly, 2007). No entanto, uma máquina administrativa pesada, Fun, resulta em efeitos espaciais negativos sobre as taxas de crescimento dos municípios vizinhos. Isto é, a região como um todo se beneficia da presença de funcionários mais qualificados e insulados, sendo prejudicada pela presença de uma máquina administrativa excessivamente grande.

Os coeficientes em nível, estimados para a proporção de conselhos, Cons, e para o Índice de transparência, $T r$, são significativos ao nível de confiança de 99\%. Eles corroboram os conceitos de Poder infraestrutural (Mann, 1984) e Capacidade transformativa (Evans, 2012), evidenciam a importância da construção de arenas de diálogo entre o Estado e a sociedade, responsáveis por mobilizar iniciativas e alinhar as ações públicas e privadas (Evans, 2012; Weiss, 2018; Cingolani, 2013). A habilidade do Estado em dialogar, coordenar, criar conexões, alinhar ações e sensibilizar a iniciativa privada para interesses comuns resulta em maiores taxas de crescimento econômico (Evans et al., 1985; Amsden, 2001; Rauch e Evans, 2000; Evans, 2004; Wade, 2018).

Os modelos estimados com a adição da temperatura, Temp, e da Latitude, Lat, como instrumentos para Instituições e da taxa de Abstenção eleitoral, Abs, e do logaritmo do número de Organizações da Sociedade Civil, $O S C s$, como instrumentos para a Capacidade transformativa, Tabela 6 mostram que esses instrumentos são significativos ao nível de confiança de 99\%. A Latitude possui sinal negativo, oposto ao esperado, e indica que os municípios mais distantes da linha do equador exibem menores taxas de crescimento econômico. Os coeficientes estimados para essa variável defasada espacialmente também são significativos, a proximidade geográfica entre os municípios afeta negativamente a sua taxa de crescimento econômico. 


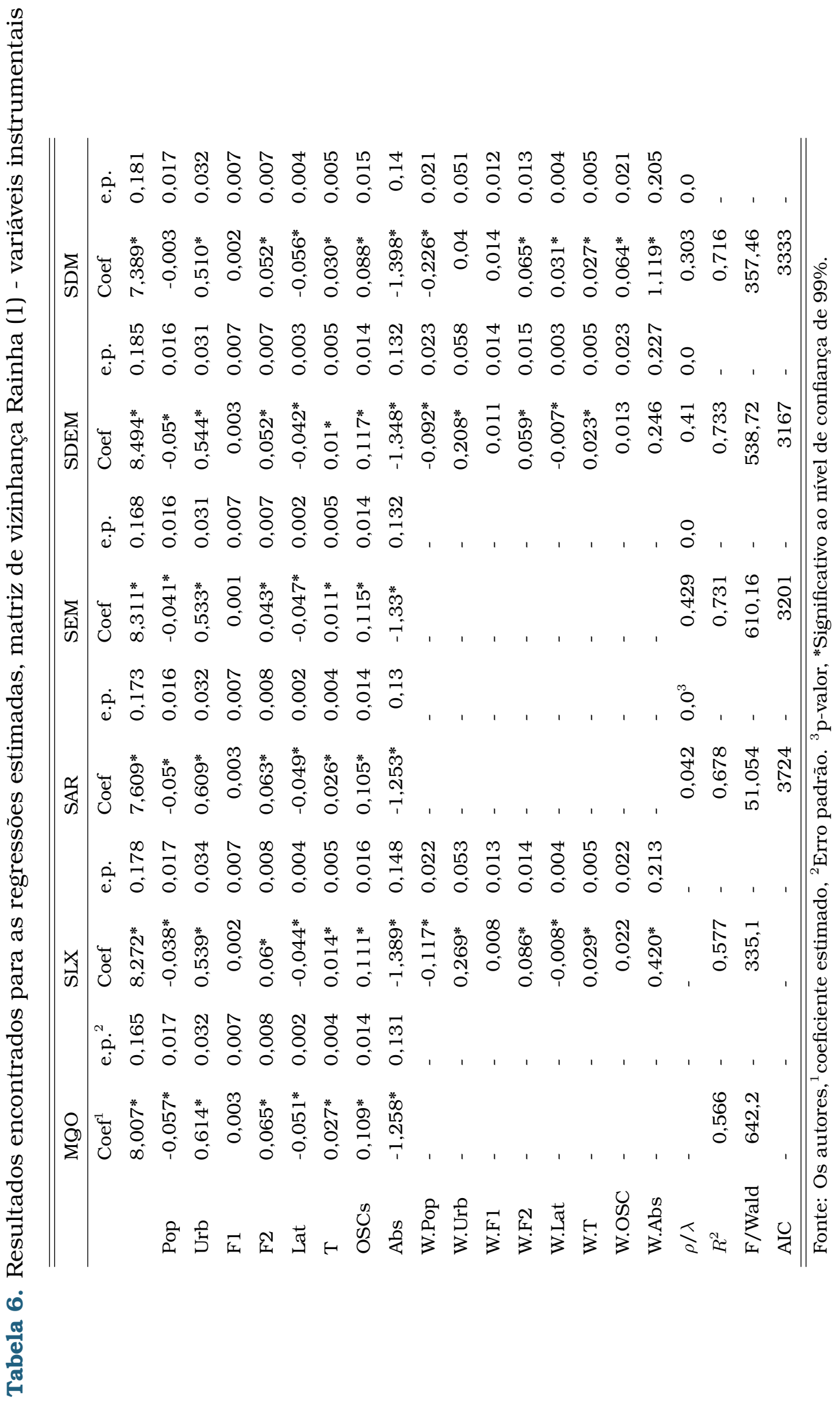


A variável Temperatura, $T$, corrobora a importância das instituições, sendo significativa ao nível de confiança de 99\% (Acemoglu e Robinson, 2012). Esse resultado mostra que a adoção de políticas de incentivo aos investimentos, Fator 2, é importante. No entanto, o processo de decisão locacional das firmas é mais amplo e a qualidade das instituições importa. Os municípios com maior regulamentação das atividades produtivas, com proteção dos direitos de propriedade e com legislações que amparam e protegem os investimentos privados conseguem auferir maiores taxas de crescimento econômico (North et al., 1990; Williamson e Masten, 1999; Hodgson, 2006, 2007; Acemoglu e Robinson, 2012). Semelhante à Leivas et al. (2015) e Arbia et al. (2010), as defasagens espaciais para a Temperatura são estatisticamente significativas ao nível de confiança de 99\%. Esse resultado indica que a capacidade institucional influencia na taxa de crescimento da renda per capita dos municípios vizinhos. A presença de melhores instituições na vizinhança provavelmente cria um cenário mais favorável aos investimentos, o que resulta em spillovers positivos que favorecem o crescimento econômico.

O logaritmo do número de Organizações da Sociedade Civil, OSCs, também exibe sinal positivo. Essa variável evidencia a importância do Capital social e, logo, da capacidade transformativa para o crescimento econômico. A construção de arenas de diálogo entre os setores público e privado possibilita a maior coordenação e a sinalização das políticas adotadas, o que se traduz em maior estabilidade econômica e confiança entre os agentes, favorecendo a organização coletiva da sociedade e o investimento produtivo (Putnam, 1993; Charron e Rothstein, 2014; Charron et al., 2017).

Ademais, a taxa de Abstenção eleitoral, Abs, exibe sinal negativo, sendo o coeficiente em nivel significativo para todas as regressões. Conforme destacado por FortinRittberger (2014); Charron e Rothstein (2014) e Charron et al. (2017), a ausência de canais de comunicação e de concertação entre as iniciativas pública e privada mina a confiança dos agentes privados, que perdem interesse pela participação política. Os resultados encontrados mostram que a menor participação no pleito eleitoral se encontra diretamente relacionada com a taxa de crescimento econômico, de modo que políticas públicas que não olham para as prioridades e interesses da sociedade local se traduzem em menor participação política, menor diálogo do Estado com a sociedade e em menores taxas de crescimento econômico.

Apenas os coeficientes defasados estimados para os modelos $S D M$ e $S L X(S D M)$ são significativos para a variável $O S C(A B S)$. Eles indicam que a maior organização coletiva dos municípios vizinhos resulta em crescimento econômico. Paradoxalmente, a menor participação política resulta em maiores taxas de crescimento econômico. De modo que a proximidade de municípios com elevado capital social e baixa participação política favorece o crescimento da renda.

Por conseguinte, os resultados encontrados fornecem evidências inovadoras para as literaturas de Capacidades estatais, políticas produtivas e Instituições. O artigo diferencia os conceitos de Capacidades estatais, políticas produtivas e Instituições 
mediante a construção de indicadores específicos, sendo inédito nesse sentido. Os resultados evidenciam a presença de complementariedades entre as políticas de desenvolvimento produtivo, a qualidade das instituições locais e a construção de arenas de diálogo com a sociedade. A presença de um corpo estatal dotado de intencionalidade, capaz de intervir na estrutura produtiva e formular políticas públicas não é condição suficiente para o crescimento econômico. As políticas produtivas também demandam canais de diálogo e legislações locais favoráveis ao pleno desenvolvimento do setor privado. Isto é, muito além de identificar e incentivar atividades chaves, os governos locais precisam desenvolver sinergias, complementaridades e laços com a iniciativa privada e cria um contexto político, econômico e institucional estável e favorável à apropriação e à autodescoberta de novas oportunidades de inovação e de investimento pelo setor privado (Hausmann e Rodrik, 2003).

\section{Considerações finais}

A literatura de capacidade estatal argumenta que a Capacidade Transformativa identifica uma dimensão específica de capacidade estatal, entendida como a habilidade do Estado em dialogar e solidarizar as forças produtivas locais de acordo com interesses em comum. No entanto, não foram encontrados estudos na literatura de desenvolvimento regional que diferenciassem essa capacidade da presença de melhores Instituições e da adoção de políticas produtivas. Destarte, o objetivo desse artigo é desenvolver indicadores específicos para os municípios brasileiros, capazes de diferenciar essas políticas e identificar quais delas contribuem para o crescimento econômico. Ferramentas de análise descritiva de dados, o coeficiente de correlação espacial $I$ de Moran e regressões espaciais são utilizadas para identificar quais dessas políticas contribuem para o crescimento econômico, a partir de dados tabulados para 4.359 municípios brasileiros.

A análise fatorial retorna dois fatores, associados à realização de políticas produtivas: Inclusão produtiva e Implantação de empreendimentos. O coeficiente $I$ de Moran global mostra que a renda apresenta elevada correlação espacial, ao passo que os indicadores que identificam a Capacidade transformativa, as Instituições e a intervenção na estrutura produtiva exibem baixa correlação espacial. O coeficiente $I$ de Moran local corrobora esses resultados, a renda apresenta elevada correlação espacial e existe um grande agrupamento de municípios com correlação Alta-Alta nas regiões Sul, Sudeste e Centro-oeste do país e de um grande agrupamento com correlação Baixa-Baixa na Região Nordeste do país. Em contrapartida, não se observa a formação de grandes agrupamentos de municípios para o coeficiente $I_{i}$ de Moran local para os demais indicadores, sendo essa uma evidência favorável ao argumento de que os municípios não possuem o hábito de copiar Instituições, Capacidades transformativas e políticas voltadas para a transformação na estrutura produtiva dos municípios vizinhos.

O teste de razão de máxima verossimilhança mostra que o modelo Espacial de Dur- 
bin $(S D M)$ e o modelo Erro Espacial de Durbin ( $S D E M)$ apresentam melhor ajuste. Isto é, a taxa de crescimento na renda per capita exibe efeitos espaciais, sendo influenciada pela renda per capita dos municípios vizinhos, pela defasagem espacial nas variáveis explicativas e pela ocorrência de choques estocásticos nos municípios contíguos. Os coeficientes estimados para a Implantação de empreendimentos são positivos e significativos ao nível de confiança de 99\%, eles demonstram que as políticas produtivas contribuem para o crescimento econômico dos municípios brasileiros. As variáveis Conselhos e Transparência municipal, utilizadas para mensurar a presença de Capacidades transformativa, e os instrumentos Organizações da Sociedade Civil e Taxa de Abstenção eleitoral, utilizados tratar os problemas de endogeneidade e de causalidade reversa associado a essas variáveis, também são significativos, a presença de capacidade transformativa contribui para o crescimento econômico. Resultado semelhante é encontrado para Instituições e seus respectivos instrumentos, Latitude e Temperatura, exceto pelo fato de a Latitude possuir sinal negativo. Assim, os resultados encontrados corroboram parcialmente a hipótese levantada, a Capacidade transformativa e as Instituições contribuem para o crescimento econômico.

Destarte, o presente estudo cumpre com os objetivos. Os indicadores construídos diferenciaram os efeitos provenientes da adoção de políticas de transformação na estrutura produtiva, daqueles relacionados à construção de arenas de diálogo com a sociedade e à presença de melhores Instituições. Cabe ressalvar que o objetivo desse artigo não é afirmar que os investimentos privados não seriam efetivados na ausência da Capacidade transformativa, uma vez que o processo de decisão locacional das firmas é mais amplo. Os resultados obtidos apenas evidenciam que o maior diálogo do Estado com a sociedade pode facilitar essas decisões ao reduzir as incertezas, suprir informações, facilitar a coordenação entre os agentes e ajudar as firmas a identificarem oportunidades de investimento. Os setores públicos e privados não são vistos como agentes isolados e/ou mutuamente excludente e sim como agentes complementares, sendo a função do Estado emponderar a iniciativa privada, fornecer os insumos institucionais e informacionais necessários, coordenar e alinhar interesses e criar um contexto econômico estável e favorável ao pleno desenvolvimento desse setor. O Estado deve se manter ouvinte e atento às demandas do setor privado, que assume o papel de protagonista nas ações e políticas a serem adotadas.

Fica como sugestão para trabalhos futuros aprofundar a pesquisa por meio da construção de melhores indicadores de capacidades estatais, derivados de metodologias estatísticas apropriadas e da análise mais detalha das políticas públicas municipais voltadas para a transformação na estrutura produtiva. Evidencia-se também a necessidade de se identificar os fatores que influenciam na presença de capacidade transformativa em âmbito municipal e de indicadores capazes de abarcar a crítica realizada por Amartya Sen. 


\section{Referências}

Abrucio, F. L. e Franzese, C. (2007). Federalismo e políticas públicas: o impacto das relações intergovernamentais no Brasil. Tópicos de Economia Paulista para Gestores Públicos, 1:13-31.

Acemoglu, D. e Robinson, J. (2012). Por que as nações fracassam: as origens do poder, da prosperidade e da pobreza. Elsevier Brasil.

Aguiar, R. B. e Lima, L. L. (2019). Capacidade estatal: definições, dimensões e mensuração. Revista Brasileira de Informação Bibliográfica em Ciências Sociais, 89(1):1-28.

Almeida, E. (2012). Econometria espacial.

Almeida, E. T., Moraes Rocha, R., e Gomes, S. M. F. P. O. (2017). Economias de aglomeração e o crescimento das indústrias intensivas em tecnologia: evidências para o nordeste no período 2002-2014. Revista Brasileira de Estudos Regionais e Urbanos, 11(4):467-494.

Almeida, M. (2009). Desafios da real política industrial brasileira do século xxi. Texto para discussão, Texto para discussão.

Amsden, A. H. (2001). The rise of "the rest": challenges to the west from lateindustrializing economies. Oxford University Press, USA.

Anselin, L. (1995). Local indicators of spatial association-lisa. Geographical analysis, 27(2):93-115.

Arbia, G., Battisti, M., e Di Vaio, G. (2010). Institutions and geography: Empirical test of spatial growth models for European regions. Economic modelling, 27(1):12-21.

Barreto, R. C. S., Duarte, L. B., e Alves, A. V. S. (2018). Qualidade institucional e desenvolvimento socioeconômico dos municípios do território do Sisal, Bahia. Revista de Estudos Sociais, 20(41):109-143.

Barro, R. J. (1990). Government spending in a simple model of endogeneous growth. Journal of Political Economy, 98(5, Part 2):S103-S125.

Barro, R. J. (1991). Economic growth in a cross section of countries. The Quarterly Journal of Economics, 106(2):407-443.

Boschi, R. R. (2007). Capacidades estatais, empresários e desenvolvimento no Brasil: uma reflexão sobre a agenda pós-neoliberal. Revista do Serviço Público, 58(1):71-92.

Boschi, R. R. (2013). Capacidades Estatais para o Desenvolvimento em Perspectiva Comparada. Instituto Nacional de Ciência e Tecnologia em Políticas Públicas, Estratégias e Desenvolvimento. Brasília.

Cano, W. e Silva, A. L. G. (2010). Política industrial do governo Lula. Texto para discussão, n. 181. IE/UNICAMP. 
Casagrande, D. L., de Oliveira Hoeckel, P. H., e dos Santos, C. A. P. (2017). Convergência do pib per capita no rio grande do sul: uma análise de 2001 a 2013. Revista Brasileira de Estudos Regionais e Urbanos, 11(3):358-383.

Cerqueira, K. C. (2015). A economia política do desenvolvimentismo no Brasil: dependência da trajetória, mudança institucional e capacidades estatais. Texto para discussão.

Charron, N., Dahlström, C., Fazekas, M., e Lapuente, V. (2017). Careers, connections, and corruption risks: Investigating the impact of bureaucratic meritocracy on public procurement processes. The Journal of Politics, 79(1):89-104.

Charron, N. e Rothstein, B. (2014). Social trust, quality of government and ethnic diversity: An empirical analysis of 206 regions in Europe.

Cingolani, L. (2013). The State of State Capacity: a review of concepts, evidence and measures. UNU-MERIT.

Corrar, L. J., Dias Filho, J. M., e Paulo, E. (2009). Análise multivariada para os cursos de administração, ciências contábeis e economia. Editora Atlas.

Easterly, W. e Rebelo, S. (1993). Fiscal policy and economic growth. Journal of Monetary Economics, 32(3):417-458.

Evans, P. (1993). O estado como problema e solução. Lua Nova: Revista de Cultura e Política, (28-29):107-157.

Evans, P. (2002). Collective capabilities, culture, and Amartya Sen's development as freedom. Studies in comparative international development, 37(2):54-60.

Evans, P. (2004). Autonomia e parceria: estados e transformação industrial. UFRJ.

Evans, P. B. (2012). Embedded autonomy: States and industrial transformation. Princeton University Press.

Evans, P. B., Rueschemeyer, D., e Skocpol, T. (1985). Bringing the state back in. Cambridge University Press.

Faria, W. R., Betarelli Júnior, A. A., Santiago, F. S., dos Reis, F. S., e Montenegro, R. L. G. (2018). Estrutura socioeconômica, vantagens competitivas e padrão regional: avaliando as disparidades da zona da mata de minas gerais em 2010. Revista Brasileira de Estudos Regionais e Urbanos, 12(1):51-73.

Ferreira Neto, A. B. (2014). Convergência de renda e convergência de consumo de energia elétrica: uma análise comparativa. Revista Brasileira de Estudos Regionais e Urbanos, 8(2):123-138.

Fortin, J. (2012). Is there a necessary condition for democracy? the role of state capacity in postcommunist countries. Comparative political studies, 45(7):903-930. 
Fortin-Rittberger, J. (2014). Exploring the relationship between infrastructural and coercive state capacity. Democratization, 21(7):1244-1264.

Gerschenkron, A. (1968). El atraso económico en la perspectiva histórica. Investigación Económica, 28(111/112):141-165.

Gomes, E. R. (2016). Relações Estado-Sociedade e novas capacidades estatais para o desenvolvimento entre os países do BRICS: o Brasil em perspectiva comparada com a África do Sul e a Índia. Capacidades Estatais em Países Emergentes-o Brasil em perspectiva comparada. Rio de Janeiro: IPEA.

Gomide, A. d. Á., Silva, F. d. S., e Pires, R. R. C. (2014). Capacidades estatais e politicas públicas: passado, presente e futuro da ação governamental para o desenvolvimento. Instituto de Pesquisa Econômica Aplicada (Ipea).

Grin, E. J., do Nascimento, A. B., Abrucio, F. L., e Fernandes, A. S. (2018). Sobre desconexões e hiatos: uma análise de capacidades estatais e finanças públicas em municípios brasileiros. Cadernos Gestão Pública e Cidadania, 23(76).

Hausmann, R. e Rodrik, D. (2003). Economic development as self-discovery. Journal of Development Economics, 72(2):603-633.

Hodgson, G. M. (2006). What are institutions? Journal of Economic Issues, 40(1):1-25.

Hodgson, G. M. (2007). Institutions and individuals: interaction and evolution. Organization Studies, 28(1):95-116.

IBGE (2016). Perfil dos municípios brasileiros 2015. Instituto Brasileiro de Geografia e Estatística. Rio de Janeiro.

IBGE (2019). Perfil dos municípios brasileiros 2018. Instituto Brasileiro de Geografia e Estatística. Rio de Janeiro.

Jacobs, J. (2016). The economy of cities. Vintage.

Jaguaribe, A. (2015). Capacidades estatais comparadas: China e a reforma do sistema nacional de inovações.

Johnson, C. (1982). MITI and the Japanese miracle: the growth of industrial policy, 1925-1975. Stanford University Press.

Keynes, J. M. (2018). The general theory of employment, interest, and money. Springer.

Leivas, P. H. S., Menezes, G. R., Cravo, T. A., e dos Santos, A. M. A. (2015). A geografia das instituições: uma abordagem espacial para os municípios brasileiros. Revista Brasileira de Estudos Regionais e Urbanos, 9(2):169-185.

LeSage, J. P. (2014). What regional scientists need to know about spatial econometrics. Available at SSRN 2420725. 
Lucas, R. E. (1988). On the mechanics of economic development. Journal of Monetary Economics, 22(1):3-42.

Mann, M. (1984). The autonomous power of the state: its origins, mechanisms and results. European Journal of Sociology/Archives Européennes de Sociologie/Europäisches Archiv für Soziologie, 25(2):185-213.

Marenco, A. (2017). Burocracias profissionais ampliam capacidade estatal para implementar políticas? governos, burocratas e legislação em municípios brasileiros. Dados, 60(4): 1025-1058.

Marshall, A. (1920). Principles of Economics; An Introductory Volume Macmillan and Co. London, UK.

Mazzucato, M. (2014). O estado empreendedor: desmascarando o mito do setor público vs. setor privado. Portfolio-Penguin.

North, D. C. et al. (1990). Institutions, institutional change and economic performance. Cambridge university press.

Oliveira, A. S. A., Hasegawa, M. M., e Thomaz, R. A. (2018). Gastos públicos e crescimento econômico: uma análise para os municípios paranaenses. Revista Brasileira de Estudos Regionais e Urbanos, 12(4):397-416.

Painter, M. e Pierre, J. (2005). Unpacking policy capacity: Issues and themes. In: Challenges to state policy capacity, Página 1-18. Springer.

Pires, R. R. C. e Gomide, A. d. Á. (2016). Governança e capacidades estatais: uma análise comparativa de programas federais. Revista de sociologia e politica, 24(58):121143.

Putnam, R. (1993). The prosperous community: Social capital and public life. volume 13. The American Prospect.

Rauch, J. E. e Evans, P. B. (2000). Bureaucratic structure and bureaucratic performance in less developed countries. Journal of Public Economics, 75(1):49-71.

Rodrik, D. (1998). Why do more open economies have bigger governments? Journal of Political Economy, 106(5):997-1032.

Romer, P. M. (1986). Increasing returns and long-run growth. Journal of Political Economy, 94(5):1002-1037.

Santana, A. S. e Barreto, R. C. S. (2016). Qualidade institucional e desempenho econômico: análise empírica dos municípios brasileiros, 2010. Revista Brasileira de Estudos Regionais e Urbanos, 10(2):253-271.

Santana, C. H. V. (2015). Políticas de infraestrutura energética e capacidades estatais nos brics. Texto para discussão, Texto para Discussão. 
Silva, J. C. A., Bellei, M., Cittadin, I., e Menezes, G. R. (2018). Um estudo da convergência de renda per capita entre os municípios catarinenses. Revista Brasileira de Estudos Regionais e Urbanos, 12(4):504-520.

Solow, R. M. (1956). A contribution to the theory of economic growth. The quarterly journal of economics, 70(1):65-94.

Stein, G. d. Q. (2016). Política industrial no século XXI: capacidades estatais e a experiência brasileira (2003-2014).

Suzigan, W. (2017). Elementos essenciais da politica industrial. Metamorfoses do capitalismo e processos de catch-up. Belo Horizonte: UFMG.

Suzigan, W. e Furtado, J. (2006). Política industrial e desenvolvimento. Brazilian Journal of Political Economy, 26(2):163-185.

Swan, T. W. (1956). Economic growth and capital accumulation. Economic Record, 32(2):334-361.

Tilly, C. (2007). Democracy. Cambridge University Press.

Wade, R. (2018). Governing the market. Princeton University Press.

Weber, M. (1994). Economia e Sociedade: fundamentos da sociologia compreensiva, volume 1. Brasília: Editora da UnB.

Weiss, L. (2018). The myth of the powerless state. Cornell University Press.

Williamson, O. e Masten, S. (1999). The economics of transaction costs. Texto para discussão, Edward Elgar Publishing.

(ब) Ev Este artigo está licenciado com uma CC BY 4.0 license. 